\title{
Gender Disparities and Long-Term Changes of HIV/AIDS Incidence Rate in China and the U.S. From 1994-2019: Age-period-cohort Analysis
}

Yudiyang Ma

Wuhan University

Yiran Cui

Wuhan University

Qian Hu

Huazhong University of Science and Technology

Chuanhua Yu ( $\nabla$ yuchua@whu.edu.cn)

Wuhan University

\section{Research Article}

Keywords: HIV, Incidence, Gender disparities, Age-period-cohort effect, Trend

Posted Date: December 9th, 2020

DOl: https://doi.org/10.21203/rs.3.rs-113701/v1

License: (c) (i) This work is licensed under a Creative Commons Attribution 4.0 International License. Read Full License 


\section{Abstract}

Background: HIV/AIDS is a serious sexually transmitted disease with poor prognosis. So statistical data on burden of HIV/AIDS incidence and epidemic characteristics are valuable for policy making and reducing healthcare costs. This study aims to explore gender disparities of HIV/AIDS incidence and relative risks of HIV/AIDS incidence by gender and age groups in China and U.S.

Methods: We extracted data from the 2019 Global Burden of Disease study and compared epidemic characteristic and gender disparities between China and U.S. Then we employed APC model to estimate age-period-cohort effect of HIV/AIDS incidence in both countries.

Results: ASIR in China kept growing between 1994 and 2004 then fell to the level of mid-1990s but in U.S. ASIR increased in the past decade. There existed a huge and continuous expanding gender gap in U.S. while it came to widen in China before 2005 then shrunk during 2005-2019. APC analysis showed the age effect and period effect were consistent to the result of incidence comparison between male and female: gender disparities increased with progress of time in both countries and men had higher incidence of HIV/AIDS when they became old in China. Cohort effect indicated later birth groups bear relatively higher risks of incidence than earlier birth groups.

Conclusions: large gender disparities could worsen the HIV epidemic situation. In the U.S., disparities continuously expanded meanwhile incidence of HIV/AIDS was increasing, while gap was under control in China and incidence curbed. Analyzing by APC model, besides younger age groups exposed to high risks of HIV/AIDS incidence in both countries, elder citizens in China faced higher risks which implies aging of population may lead another wave of HIV/AIDS epidemic. Therefore, both young and old age groups deserve to be noticed by police-makers and narrow gender disparities should put on agenda.

\section{Introduction}

HIV/AIDS is a serious sexually transmitted disease with poor prognosis, it is no more than a public health issue but a social problem[1]. Four decades after its emergence, HIV remains a leading cause of mortality in STD and continues to threaten millions of people's health worldwide [2, 3]. According to the definition by the Global Burden of Disease Study 2019[4], HIV lead to a variety of opportunistic infections and the disease burden caused by AIDS is not reduced greatly even advanced in medicine. HIV/AIDS is still an incurable disease in present[5], there is no treatment or prophylaxis that can cease disease progression, existing therapeutic regimes such as antiretroviral therapy (ART) and methadone maintenance treatment (MMT) just delay disease progression, therefore, it cause much of health care costs lost.

China is most powerful developing country with the largest population, so the impact of communicable diseases is still tricky. The HIV epidemic in China mainland started from outbreaks in group of people who injected drugs by sharing common syringe needles in the remote southeast area in the late 1980s, from then to the mid-1990s, HIV propagated gradually from Yunnan Province to other Chinese regions along the drug trafficking routes, it also spread from injection drug users to multiple sexual partners[6]. 
With the development of society, the patterns of transmission had evolved, HIV infections in injecting drug users fell and cases among illegal blood donors had been eliminated, as the law enforcement cracked down on unscrupulous blood harvesters in the mid and late 1990s[7]. Sexual transmission became the main route of HIV spreading in China[8].According to recent studies[9], the rising part of newly confirmed patients ascribed to the sexual contact transmission had increased from $11 \%$ in 2005 to $96 \%$ in 2017 , the heterosexual contact transmission accounted for $59 \%$ while the homosexual contact transmission accounted for $26 \%$.

This shift of epidemiological features were similar to other country like the U.S., which also had substantial changes in the subsets of vulnerable people who were disproportionately represented in HIV/AIDS incident cases[10]. After the first cases of HIV infected patient reported in 1981, routine screening for HIV in medical settings had been introduced in the U.S., new HIV infected patients were diagnosed and then reached to a high level in late-1980s[11, 12].

Similarities in the rapid economic growth, large ethnic diversity, geographic expansion and the institutional transition make the comparison in China and the United States become possible[13]. In term of the epidemiological characteristics of HIV/AIDS, China fall about a decade behind the U.S. in the HIV/AIDS[14]. In other words, the HIV/AIDS epidemic in China is going through what had experienced previously in the U.S. Therefore, by making a comparison between China and the U.S., we could grasp the nature and future of HIV/AIDS and put forward targeted primary or secondary prevention. It can help governments mitigate the burden of disease, reduce healthcare costs and provide constructive guidelines for other countries worldwide to mitigate influences derive from the spreading trend of HIV/AIDS

\section{Methods}

\subsection{Data Sources}

Data in this study obtained from global burden of diseases (GBD) 2019 study. The GBD study made a yearly estimation on 195 countries and territories from 1990 to 2019 . The study extracted relative risks and exposure estimates from 46,749 randomized controlled trials, cohort studies, household surveys, census data, satellite data, and other sources[15].In short, the GBD study 2019 is a systematic, scientific effort contributed by the Institute for Health Metrics and Evaluation(IHME) to quantify the comparative magnitude of health loss due to diseases, injuries, and risk factors by age, sex, and geographies for specific points in a series time.

We selected the data of both genders in China and the U.S., data such as incidence of HIV, the crude incidence and the age-standardized incidence rate of HIV/AIDS in all age groups from 1994 to 2019 were extracted from the GBD results tool (available at the website http://ghdx.healthdata.org/gbd-results-tool).

\subsection{Statistical Analysis}




\subsubsection{Age-Period-Cohort Analysis}

We introduced the age-period-cohort model(APC) which is often used in the fields of sociology, population and epidemiology[16, 17]. It can isolate effects of different ages, periods, and cohorts on study outcomes, this model is often used in long-term trend studies such as social changes, disease causes, aging, population process and dynamic researches[18]. The APC model could express as follow:

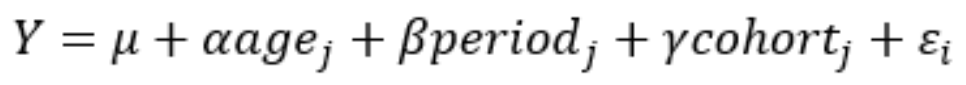

In this model, $Y$ represents the response variable in APC model, $\mu$ represents the intercept item, $a, \beta, Y$ respectively, represent the coefficients of age, period and cohort of APC model, $\varepsilon_{i}$ in APC model represent the residual. Age effects indicate the different risks of various outcomes during different periods of life; period effects reflect population-wide exposure at a circumscribed point in time; and cohort effects generally represent the disparities in risk across birth cohorts $[19,20]$. Collinearity problem caused by the linear relationship between age, period and cohort can be further express as: cohort = period - age [21, 22].

Therefore, we conducted Intrinsic Estimator(IE)[18] to estimate the coefficient.

\subsubsection{Data Arrangement}

We chopped the time series from 1994 to 2019 into 5 consecutive intervals, the period from 1990 to 1993 were not a 5 years continuity interval so the data before 1994 were discarded. Successive 5 -year age groups from 15-19 to 75-79 years old were divided, individuals younger than 15 years and older than 80 years were excluded. Besides these, 18 consecutive cohorts were allotted, including those born from 1919-1923 to 2004-2009. For the calculation of RR, we chose the mean level in age, period and cohort as reference groups, and then calculated the difference between reference groups and other groups. This process of analysis conducted by Stata 14.0 software (StataCorp, College Station, TX, USA). Wald chisquare tests were used to calculate the significance of the estimable parameters and functions. All statistical tests were 2-sided and the corresponding value of $p<0.05$ means a vivid significance statistically.

\section{Results}

\subsection{Overall Trends of HIV/AIDS Age-standardized Incidence in China and the U.S.}


Figure 1 presented time sequence changes of the age-standardized incidence rate (ASIR) of HIV/AIDS in male and female of China and the U.S. from 1994 to 2019. As we can see, male invariably higher than female in China and U.S. ASIR of both male and female in the U.S. rose first and hit a peak in 1997, after plummeted and went through a smooth period, it turned to gradually went up and attain to a high level in 2019. While in male of China the ASIR of HIV/AIDS from 1.76/100,000 in 1994 to $6.34 / 100,000$ in 2005, which represented an upward trend, then it dropped from 6.19/100,000 in 2006 to $3.30 / 100,000$ in 2019, curve of female remained in a bottom and followed male's trend, from 0.98/100,000 in 1994 to $1.07 / 100,000$ in 2019 , the range of changes did not exceed 1.5/100,000.

\subsection{Gender Disparities Between Male and Female in Both Countries}

Gender gaps between male and female can be seen clearly in Figure 1, it expanded gradually before 2006 in China, raising from 0.78/100,000 in 1994 to 4.07/100,000 in 2006, but had shrunk from 3.99/100,000 in 2007 to $2.23 / 100,000$ in 2019. A huge gap exists in U.S. and expanded from 8.38/100,000 in 1994 to 17.08/100,000 in 2019. Albeit gap decreased a little from 1997 to 2001, this promising trend did not keep hold. It still maintained an exaggerated gap and had no sign of narrowing. We classified 13 age groups into three stage of life: young age(15-34), middle age(35-59) and old age(60-79). In Figure 2, gender difference in HIV/AIDS incidence increased gradually with age and was readily apparent in China. Ratio in young age was modest in three stage further demonstrated that young people are most vulnerable to infection whatever male and female. At the same time, with the change of time, almost all age groups showed an increase in the sex ratio. However, Figure 2 can't indicate gender disparities in which country was much severer, it only reflected trends of gender disparities with time change or with age change, this can be attributed to incidence rate of HIV/ADIS in U.S. was considerably higher than China. Rate ratio cover the gender disparities in some degree, for example, the incidence rate was $26 / 100,000$ in male and $21 / 100,000$ in female in U.S. while $2 / 100,000$ in male and $0.6 / 100,000$ in female in China, the former rate ratio was 1.24 but latter was 3.33 .

The RR of a particular age, period, or birth cohort was calculated based on these coefficients of age, period, and cohort effects estimated by using the age-period-cohort model (Table A1 and Table A2).

\subsubsection{Age effect}

Relative risks (RRs) of HIV/AIDS incidence in China and the U.S. were depicted in Figure3,4,5. Age effect could be seen in Figure 3. In groups younger than 50 years old, we found the fluctuations of RRs, which rose from 15-19 age group in a quick speed and reached peak in 25-29 age group then had a steep slide in middle-aged groups (30-34 to 45-49 age groups), were resemblant in both countries and genders. In the peak of young age, risks of HIV/AIDS in the U.S. were 1.5 and 1.4 times larger than China for male and female respectively. Although risks of both male and female in the U.S. had a steep glide and hit a rock- 
bottom position in 75-79 age group, trend of old groups in China was in opposite. Curve of RRs exhibited an uninterrupted escalating trend from 45-49 to 75-79 age groups in male of China. For female, down trend among 60-64 to 65-69 age groups mitigated previous uptrend, risks of both gender in China surpassed the first peak and reached to a new high in 75-79 age group. In this group, risks were 9.5 and 8.4 times larger than male and female in the U.S. respectively. This finding indicate that younger groups exposed to high risks of HIV/AIDS incidence, but for China, groups over 70 years old climbed in an exaggerate speed and bear higher risks than younger groups ultimately.

\subsubsection{Period effect}

We observed RRs of HIV/AIDS incidence in the U.S. moderately fluctuated at low level with advancing time in Figure 4. However, it showed an increasing trend in past decade and RRs of incidence increased by 1.6 times in men and 1.2 times in women. Risks in China plotted an oscillating trend. Curves did not display a sign of decline until it reached the summit in 2004, at this point risks were 1.87 times and 1.9 times larger than male and female in the U.S., from then on, upward momentum of risks was curbed and RRs of incidence glided down to the level of 1994 finally in China.

\subsubsection{Birth cohort effect}

Birth cohort effect on HIV/AIDS incidence presented in Figure 5. RRs of incidence almost same in male and female. Compare to the U.S., RRs of incidence had more complex fluctuations in China.

Curves showed an upside-down $V$ trend which indicated that RRs of incidence rose up first then drop down from 1919-1923 to 1979-1983 birth groups, risks began augment from 1989-1993 birth groups then acquired its highest value in 2004-2009 birth group. In the U.S. risks of incidence hiked remarkably to the first peak then experienced a transitory dip from 1919-1923 to 1934-1938 birth cohort, after a succession of steady growth, a new height appeared in 1984-1989 cohort group. From 1989-1993 to 2004-2009 birth groups, RRs increased by $227.6 \%$ in male and $329.0 \%$ in female in China; in the U.S., it increased by $238.2 \%$ in male and $290.1 \%$ in female. In term of birth cohort, later birth groups exposed relatively higher risks of HIV/AIDS incidence than earlier birth groups.

\section{Discussion}

In the present study, we conducted a comparison about gender disparities of HIV infection among young, middle and old age groups and performed an APC model to estimate the age, period, and birth cohort effects of incidence in China and the U.S. The result of comparison kept parallel to age and period effect: gender disparities increased with progress of time in both countries and men had higher incidence of HIV/AIDS when they became old in China. Cohort effect denoted latter birth groups bear higher risks of infection than earlier birth groups. 
Gender disparities in both countries can be explained by followed reasons. Firstly, Changes of the demographic characters aggravated this issue. According to a Chinese census[23], the sex ratios of male to female at birth rose since 1990.The same concern existed in the U.S. as well. More HIV infections among males eventually lead a larger gender gap in HIV/AIDS incidence. Secondly, sexual transmission, especially men who have sex with men(MSM) in the U.S., played as a leading cause of gender disparities[24, 25]. It means men were at a higher risk of HIV exposure. For China, sexual liberation acted as a key factor in the rapid dispersion of HIV. Male-male sex had been legalized in China since 1997[6] since then homosexual was not as unacceptable as before. It undoubtedly fastens the transmission of HIV in male. Thirdly, men made up the majority in the large mobile populations which were proved as a high risk group of HIV infections in China[26]. Finally, treatment of HIV/AIDS had been shown to prevent HIV transmission[27-29] and certainly had affected its distribution and evolution. Previous studies suggested some HIV/AIDS treatments such as ART benefited woman more[30], which means women were respond to some HIV/AIDS therapies or interventions positively and it in turn protected them from HIV infections[31]. To sum up, as the gender gap widens with time change, female seems safer than male, but if more men become infected with HIV, women will eventually be threatened.

For the age effect, younger age groups are easier to addicted to high-risk sexual behaviors or drug use and assume high risks of HIV infection proved a known fact around the world[32]. A more serious fact is much more risks of HIV/AIDS in Chinese senior citizens, which may imply that ageing and without social assistance drive the elders under the threaten of HIV/AIDS. Chinese residency system reform in 1980 compelled millions of elder migrants left their native places[33]. Education and expertise scarce compelled middle- or elder-groups away from home to earn a living. Lack of family support might generate influences on opportunistic infections among the older generation[34]. Compared to nonmigrants living with families, elder migrants were far away from home and may seek sexual services. Unprotected sexual intercourse was common in these groups due to short of education and out of pocket[35]. Hence sexually risky behaviors caused an exacerbation of the HIV/AIDS epidemic in older groups. Besides, sexual demands of the elders are often neglected by their partners as well as by the society[36], for the sake of dispelling loneliness, they chat on internet via various kind of mobile applications and date with unfamiliar persons under the background of information era[37]. Being short of self-protection consciousness among older adults eventually increases the risk of HIV/AIDS acquisition. If these issues get no attention from government, acute aging problems in China[38] may intensify the current situation in HIV/AIDS incidence and lead to a new wave of increasing.

Period effect presented RRs held steadily in a low level in the United State when birth cohort and age effects were both controlled, but it turned to increase in past decade. The U.S. healthcare system is the largest and most advanced in the world[39], a series of therapies in treating HIV like the introduction of the first nucleoside analogue reverse transcriptase inhibitor in 1987[40], the expanding of AIDS surveillance definition in 1993[41] and protease inhibitors in 1995[42], were proved effective at a population level. Under this circumstance, a decline trend was exhibited in RRs of HIV/AIDS in both gender during 1999 to 2009. Nevertheless, advanced therapies on patients after HIV infection just restricted it spreading but can't eliminate the virus completely[43], uncontrollable high risk behaviors 
under its culture background[44] may cause HIV resurgence. At the same time, the advent of some aggressive treatment regimens accompanied with side-effects too[45]. Suffering sever side-effect profiles made potential patients hesitate to receive therapies or not and eventually resulted more new infections continued to occur.

As for China, our study showed that the trend of period effect was consistent to its ASIR. According to former studies[46, 47], time before 2005 were described as the "rapid expansion phase". Upward trend of ASIR in China could ascribe to the reform and opening-up policy. Prior to the reform and opening-up policy, traditional Chinese held that premarital or extramarital sex were shameful, so their attitudes on sex only limited to marital sex and the purpose only for reproductions[48]. It was undeniable that the introduction of "Open Door Police" brought traditional Chinese people wide acceptance of pre- and extramarital sex[49,50]. Considering other factors such as living with hemophilia[26], drug addiction, illegal plasma donors[51], homosexual and heterosexual contact[6], all these caused an escalation in RRs previous to 2004. For the purpose of repressing the upsurging trend of HIV/AIDS. In 2003, Chinese government announced its "Four Frees and One Care" policy[52]. In 2005, a web-based HIV reporting system integrated the HIV and AIDS surveillance system were establish[53]. In 2006, the National Center for AIDS/STD Control and Prevention (NCAIDS) at the Chinese Center for Disease Control and Prevention (China CDC) launched its national, web-based HIV/AIDS information system, the Comprehensive Response Information Management System (CRIMS)[53]. Together with delivering health promotion strategies in social network, strengthening sexual health services and partner services[54,55], these measures not only provided researchers a comprehensively understand about the epidemic features of HIV, but made a breakthrough contribution on curbing HIV.

Cohort effects in China and the U.S. should be explained carefully because of the resemblance in their trends: the cohort effect revealed that people among latter birth groups had a relatively higher risks than earlier birth groups. Changing of background can be regarded as a predominant reason, latter birth cohort groups in their adolescence and young adulthood, a considerable biologic, physiologic even mental changes took place[56], in addition to younger generations enjoyed much greater freedoms today in thought, speech, and choices, including sexual behaviors, thus they were easier to get hooked on some risk factors of HIV/AIDS such as high-risk sexual behaviors or taking drugs[8]. It's predictable that risk of incidence will drop down quickly when they farewell to their young age. Therefore, latter birth cohort groups bear higher risk of HIV/AIDS incidence compare to earlier birth cohort groups.

\section{Limitations}

In regard of constraints in our study, initially, the data included in the study was extracted from the latest data in GBD 2019, it was undenied that certain deviations in the completeness and accuracy of HIV/AIDS incidence rate were inevitable. Although the GBD 2019 adapted numerous adjustments and corrections to the source, collation, and evaluation of the HIV/AIDS incidence rate data to enhance data accuracy and comparability, refraining from data inaccuracy thoroughly seemed impossible. Besides, the shortcomings exist in APC model may cause its accuracy to be affected, so other sophisticated models should be 
applied in future studies to explore the nature of HIV/AIDS precisely, this will be a further step for our human to quest for drug to cure rampant HIV. Finally, giving that enormous population and complex demographic characteristics in both countries, more adequate data are needed to provide robust evidences of location or ethnic effect on HIV/AIDS incidence. Considering all above limitations, we will further concentrate on the model upgrading and data updating to obtain more accurate analysis results.

\section{Conclusions}

The ASIR of HIV/AIDS showed an oscillating trend which increased to peak between 1994 and 2004 then fell to the level of mid-1990s. Despite ASIR in China was much lower than the U.S., the virus had not yet been eliminated. In U.S., previous interventions and therapies worked but it still fell short thus HIV incidence came to ascended over the past decade. Large gender disparities could worsen the HIV epidemic situation. In the U.S., disparities continuously expanded meanwhile incidence of HIV/AIDS was increasing, while gap was under control in China and incidence curbed. Analyzing by APC model, not only younger age groups and latter birth groups exposed to high risks of HIV/AIDS incidence, elder citizens in China also faced higher risks than U.S which implies aging of population may lead another wave of HIV/AIDS epidemic. Therefore, both young and old age groups deserve to be noticed by police-makers and narrow gender disparities should put on agenda.

\section{Declarations}

\section{Ethics approval and consent to participate}

Not applicable.

\section{Consent for publication}

Not applicable.

\section{Availability of data and materials}

The datasets generated and analyzed during the current study are available in the GBD results tool repository, http://ghdx.healthdata.org/gbd-results-tool.

\section{Competing interests}

Not applicable.

\section{Funding}


The study was funded by the National Key Research and Development Program of China [grant numbers 2018YFC1315302, 2017YFC1200502] and the National Natural Science Foundation of China [grant number 81773552].

\section{Authors' contributions}

Yudiyang Ma designed the study, implemented the study protocol, collected and analyzed data and wrote the first manuscript. Yiran Cui directed statistical analyses of the data and revised the paper. Qian Hu analyzed and interpreted the data. Chuanhua Yu also revised the manuscript. All authors contributed to the discussion, reviewed and edited the manuscript, and approved the final manuscript.

\section{Acknowledgements}

We appreciate the works by the Global Burden of Disease study2019 collaborators.

\section{References}

1. Hogg R, Cahn P, Katabira ET, Lange J, Samuel NM, O'Shaughnessy M, Vella S, Wainberg MA, Montaner J: Time to act: global apathy towards HIV/AIDS is a crime against humanity. The Lancet 2002, 360(9347):1710-1711.

2. Dwyer-Lindgren L, Cork MA, Sligar A, Steuben KM, Wilson KF, Provost NR, Mayala BK, VanderHeide JD, Collison ML, Hall JB et al: Mapping HIV prevalence in sub-Saharan Africa between 2000 and 2017. Nature 2019, 570(7760):189-+.

3. Frank TD, Carter A, Jahagirdar D, BiehI MH, Douwes-Schultz D, Larson SL, Arora M, Dwyer-Lindgren L, Steuben KM, Abbastabar $\mathrm{H}$ et al: Global, regional, and national incidence, prevalence, and mortality of HIV, 1980-2017, and forecasts to 2030, for 195 countries and territories: a systematic analysis for the Global Burden of Diseases, Injuries, and Risk Factors Study 2017. The Lancet HIV 2019, 6(12):e831-e859.

4. James SL, Abate D, Abate KH, Abay SM, Abbafati C, Abbasi N, Abbastabar H, Abd-Allah F, Abdela J, Abdelalim A et al: Global, regional, and national incidence, prevalence, and years lived with disability for 354 diseases and injuries for 195 countries and territories, 1990-2017: a systematic analysis for the Global Burden of Disease Study 2017. The Lancet 2018, 392(10159):1789-1858.

5. Li Z, Teng Z, Miao H: Modeling and Control for HIV/AIDS Transmission in China Based on Data from 2004 to 2016. Comput Math Methods Med 2017, 2017:8935314.

6. Wu Z, Chen J, Scott SR, McGoogan JM: History of the HIV Epidemic in China. Current HIV/AIDS reports 2019, 16(6):458-466.

7. Qian HZ, Vermund SH, Wang N: Risk of HIV/AIDS in China: subpopulations of special importance. Sex Transm Infect 2005, 81(6):442-447. 
8. Jia Z, Wang L, Chen RY, Li D, Wang L, Qin Q, Ding Z, Ding G, Zang C, Wang N: Tracking the evolution of HIV/AIDS in China from 1989-2009 to inform future prevention and control efforts. PloS one 2011, 6(10):e25671.

9. Wu Z, McGoogan JM, Detels R: The enigma of the HIV epidemic in China. Clin Infect Dis 2020.

10. Vermund SH: HIV/AIDS trends in China. The Lancet Infectious Diseases 2013, 13(11):912-914.

11. Hall HI, Geduld J, Boulos D, Rhodes P, An Q, Mastro TD, Janssen RS, Archibald CP: Epidemiology of HIV in the United States and Canada: Current Status and Ongoing Challenges. Jaids-J Acq Imm Def 2009, 51:S13-S20.

12. Boulos $D$, Yan P, Schanzer D, Remis RS, Archibald CP: Estimates of HIV prevalence and incidence in Canada, 2005. Can Commun Dis Rep 2006, 32(15):165-174.

13. Qiao YC, Xu Y, Jiang DX, Wang X, Wang F, Yang J, Wei YS: Epidemiological analyses of regional and age differences of HIV/AIDS prevalence in China, 2004-2016. Int J Infect Dis 2019, 81:215-220.

14. Huang MB, Ye L, Liang BY, Ning CY, Roth WW, Jiang JJ, Huang JG, Zhou B, Zang N, Powell MD et al: Characterizing the HIV/AIDS Epidemic in the United States and China. International journal of environmental research and public health 2015, 13(1):ijerph13010030.

15. Roth GA, Abate D, Abate KH, Abay SM, Abbafati C, Abbasi N, Abbastabar H, Abd-Allah F, Abdela J, Abdelalim $A$ et al: Global, regional, and national age-sex-specific mortality for 282 causes of death in 195 countries and territories, 1980-2017: a systematic analysis for the Global Burden of Disease Study 2017. The Lancet 2018, 392(10159):1736-1788.

16. Verdecchia A, Mariotto A, Capocaccia R, Mariotti S: An age and period reconstruction of the HIV epidemic in Italy. Int J Epidemiol 1994, 23(5):1027-1039.

17. Houweling H, Wiessing LG, Hamers FF, Termorshuizen F, Gill ON, Sprenger MJW: An age-period-cohort analysis of 50875 AIDS cases among injecting drug users in Europe. International Journal of Epidemiology 1999, 28(6):1141-1148.

18. Yang Y, Schulhofer-Wohl S, Fu WJJ, Land KC: The intrinsic estimator for age-period-cohort analysis: What it is and how to use it. Am J Socio/ 2008, 113(6):1697-1736.

19. Zou ZY, Cini K, Dong B, Ma YH, Ma J, Burgner DP, Patton GC: Time Trends in Cardiovascular Disease Mortality Across the BRICS An Age-Period-Cohort Analysis of Key Nations With Emerging Economies Using the Global Burden of Disease Study 2017. Circulation 2020, 141(10):790-799.

20. Holford TR: The Estimation of Age, Period And Cohort Effects for Vital-Rates. Biometrics 1983, 39(2):311-324.

21. Yang Y, Fu WJJ, Land KC: A methodological comparison of age-period-cohort models: The intrinsic estimator and conventional generalized linear models. Sociol Methodol 2004, 34:75-110.

22. Yang YC, Land KC: Ko, C.-W. (2014), Review of Age-Period-Cohort Analysis: New Models, Methods, and Empirical Applications, by Y. Yang and KC Land, Journal of the American Statistical Association, 109, 865: Comment by Fienberg, Hodges, and Luo and Replies REPLY. J Am Stat Assoc 2015, 110(509):457-457. 
23. Gao D, Zou Z, Dong B, Zhang W, Chen T, Cui W, Ma Y: Secular trends in HIV/AIDS mortality in China from 1990 to 2016: Gender disparities. PloS one 2019, 14(7):e0219689.

24. Zhang F, Dou Z, Ma Y, Zhang Y, Zhao Y, Zhao D, Zhou S, Bulterys M, Zhu H, Chen RY: Effect of earlier initiation of antiretroviral treatment and increased treatment coverage on HIV-related mortality in China: a national observational cohort study. The Lancet Infectious Diseases 2011, 11(7):516-524.

25. Shang H, Xu JJ, Han XX, Li JS, Arledge KC, Zhang LQ: Bring safe sex to China. Nature 2012, 485(7400):576-577.

26. Zhang KL, Ma SJ: Epidemiology of HIV in China - Intravenous drug users, sex workers, and large mobile populations are high risk groups. Bmj-Brit Med J 2002, 324(7341):803-804.

27. Montaner JSG, Lima VD, Barrios R, Yip B, Wood E, Kerr T, Shannon K, Harrigan PR, Hogg RS, Daly P et al: Association of highly active antiretroviral therapy coverage, population viral load, and yearly new HIV diagnoses in British Columbia, Canada: a population-based study. The Lancet 2010, 376(9740):532-539.

28. Das M, Chu PL, Santos GM, Scheer S, Vittinghoff E, McFarland W, Colfax GN: Decreases in Community Viral Load Are Accompanied by Reductions in New HIV Infections in San Francisco. Plos One 2010, 5(6).

29. Cohen MS, Chen YQ, McCauley M, Gamble T, Hosseinipour MC, Kumarasamy N, Hakim JG, Kumwenda J, Grinsztejn B, Pilotto JHS et al: Prevention of HIV-1 Infection with Early Antiretroviral Therapy. New Engl J Med 2011, 365(6):493-505.

30. Zhang FJ, Dou ZH, Ma Y, Zhao Y, Liu ZF, Bulterys M, Chen RY: Five-Year Outcomes of the China National Free Antiretroviral Treatment Program. Ann Intern Med 2009, 151(4):241-W252.

31. Dou ZH, Xu JH, Jiao JH, Ma Y, Durako S, Yu L, Zhao Y, Zhang FJ: Gender Difference in 2-Year Mortality and Immunological Response to ART in an HIV-Infected Chinese Population, 2006-2008. Plos One 2011, 6(8).

32. Lall P, Lim SH, Khairuddin N, Kamarulzaman A: Review: an urgent need for research on factors impacting adherence to and retention in care among HIV-positive youth and adolescents from key populations. J Int AIDS Soc 2015, 18(2 Suppl 1):19393.

33. Chan KW, Liu T, Yang Y: Hukou and non-hukou migrations in China: comparisons and contrasts. Int $J$ Popul Geogr 1999, 5(6):425-448.

34. Li XM, Fang XY, Lin DH, Mao R, Wang J, Cottrell L, Harris C, Stanton B: HIV/STD risk behaviors and perceptions among rural-to-urban migrants in China. Aids Educ Prev 2004, 16(6):538-556.

35. Hesketh T, Li L, Ye X, Wang H, Jiang M, Tomkins A: HIV and syphilis in migrant workers in eastern China. Sex Transm Infect 2006, 82(1):11-14.

36. Hong Y, Stanton B, Li XM, Yang HM, Lin DH, Fang XY, Wang J, Mao R: Rural-to-urban migrants and the HIV epidemic in China. Aids And Behavior 2006, 10(4):421-430.

37. Xing J, Li YG, Tang W, Guo W, Ding Z, Ding G, Wang L, Qin Q, Xu Y, Qian S et al: HIV/AIDS epidemic among older adults in China during 2005-2012: results from trend and spatial analysis. Clinical 
infectious diseases : an official publication of the Infectious Diseases Society of America 2014, 59(2):e53-60.

38. Chen $\mathrm{R}, \mathrm{Xu} \mathrm{P}$, Song PP, Wang MF, He JJ: China has faster pace than Japan in population aging in next 25 years. Biosci Trends 2019, 13(4):287-291.

39. Smith RJ, Aggarwala BD: HIV: The invisible epidemic of the United States healthcare system. Social Theory \& Health 2010, 8(1):83-94.

40. Fischl MA, Richman DD, Grieco MH, Gottlieb MS, Volberding PA, Laskin OL, Leedom JM, Groopman JE, Mildvan D, Schooley RT et al: The efficacy of azidothymidine (AZT) in the treatment of patients with AIDS and AIDS-related complex. A double-blind, placebo-controlled trial. N Engl J Med 1987, 317(4):185-191.

41. Karon JM, Fleming PL, Steketee RW, De Cock KM: HIV in the United States at the turn of the century: An epidemic in transition. Am J Public Health 2001, 91(7):1060-1068.

42. Kitchen VS, Skinner C, Ariyoshi K, Lane EA, Duncan IB, Burckhardt J, Burger HU, Bragman K, Pinching AJ, Weber JN: Safety And Activity of Saquinavir in Hiv-Infection. Lancet (London, England) 1995, 345(8955):952-955.

43. Katz I, Jha AK: HIV in the United States: Getting to Zero Transmissions by 2030. JAMA 2019, 321(12):1153-1154.

44. Paz-Bailey G, Hall HI, Wolitski RJ, Prejean J, Van Handel MM, Le B, LaFlam M, Koenig LJ, Mendoza $\mathrm{MCB}$, Rose $\mathrm{C}$ et al: HIV Testing and Risk Behaviors Among Gay, Bisexual, and Other Men Who Have Sex with Men - United States. Mmwr-Morbid Mortal W2013, 62(47):958-962.

45. Gao DS, Zou ZY, Dong B, Zhang WJ, Chen TQ, Cui WX, Ma YH: Secular trends in HIV/AIDS mortality in China from 1990 to 2016: Gender disparities. PloS one 2019, 14(7).

46. He N, Detels R: The HIV epidemic in China: history, response, and challenge. Cell Res 2005, 15(1112):825-832.

47. Hong Y, Li XM: HIV/AIDS Behavioral Interventions in China: A Literature Review and Recommendation for Future Research. AIDS and behavior 2009, 13(3):603-613.

48. Xiao ZW, Mehrotra P, Zimmerman R: Sexual revolution in China: implications for Chinese women and society. Aids Care-Psychological And Socio-Medical Aspects of Aids/Hiv 2011, 23:105-112.

49. Zheng WJ, Zhou XD, Zhou C, Liu W, Li L, Hesketh T: Detraditionalisation and attitudes to sex outside marriage in China. Cult Health Sex 2011, 13(5):497-511.

50. Cohen MS, Ping G, Fox K, Henderson GE: Sexually transmitted diseases in the People's Republic of China in Y2K: back to the future. Sexually transmitted diseases 2000, 27(3):143-145.

51. Ji GP, Detels R, Wu ZY, Yin YP: Correlates of HIV infection among former blood/plasma donors in rural China. AIDS (London, England) 2006, 20(4):585-591.

52. Sun XH, Lu F, Wu ZY, Poundstone K, Zeng G, Xu P, Zhang DP, Liu KM, Liau A: Evolution of informationdriven HIV/AIDS policies in China. Int J Epidemiol 2010, 39:li4-li13. 
53. Mao YR, Wu ZY, Poundstone K, Wang CH, Qin QQ, Ma Y, Ma W: Development of a unified web-based national HIV/AIDS information system in China. Int J Epidemio/ 2010, 39:li79-li89.

54. Jeffries WL, Garrett S, Phields M, Olubajo B, Lemon E, Valdes-Salgado R, Collins CB: Implementation of Evidence-Based HIV Interventions for Gay, Bisexual, and Other Men Who Have Sex with Men. AIDS and behavior 2017, 21(10):3000-3012.

55. Golden MR, Katz DA, Dombrowski JC: Modernizing Field Services for Human Immunodeficiency Virus and Sexually Transmitted Infections in the United States. Sexually transmitted diseases 2017, 44(10):599-607.

56. Garofalo R, Hotton AL, Kuhns LM, Gratzer B, Mustanski B: Incidence of HIV Infection and Sexually Transmitted Infections and Related Risk Factors Among Very Young Men Who Have Sex With Men. Jaids-J Acq Imm Def 2016, 72(1):79-86.

\section{Figures}

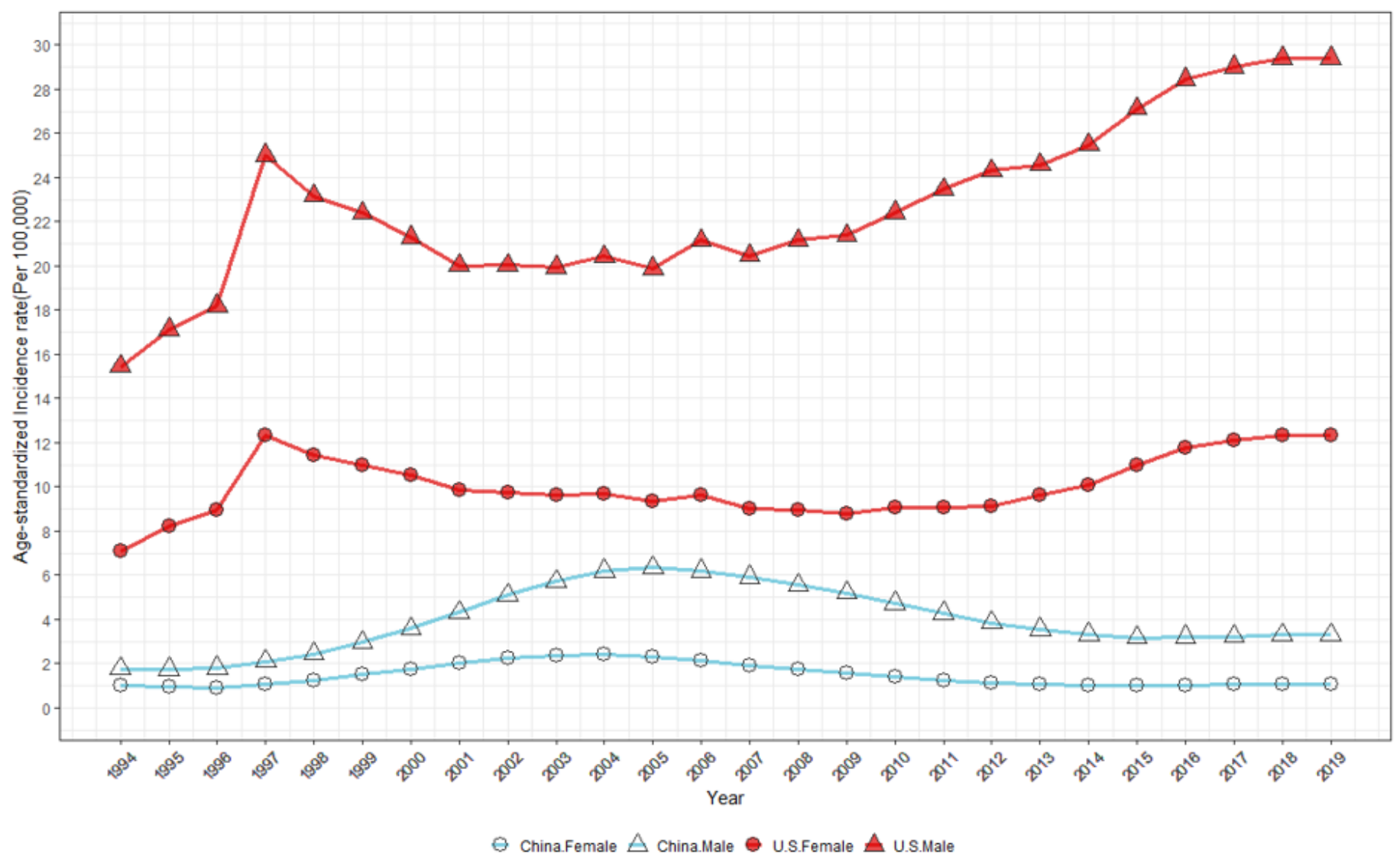

Figure 1

Age-standardized incidence rate for China and the U.S.,1994 to 2019 


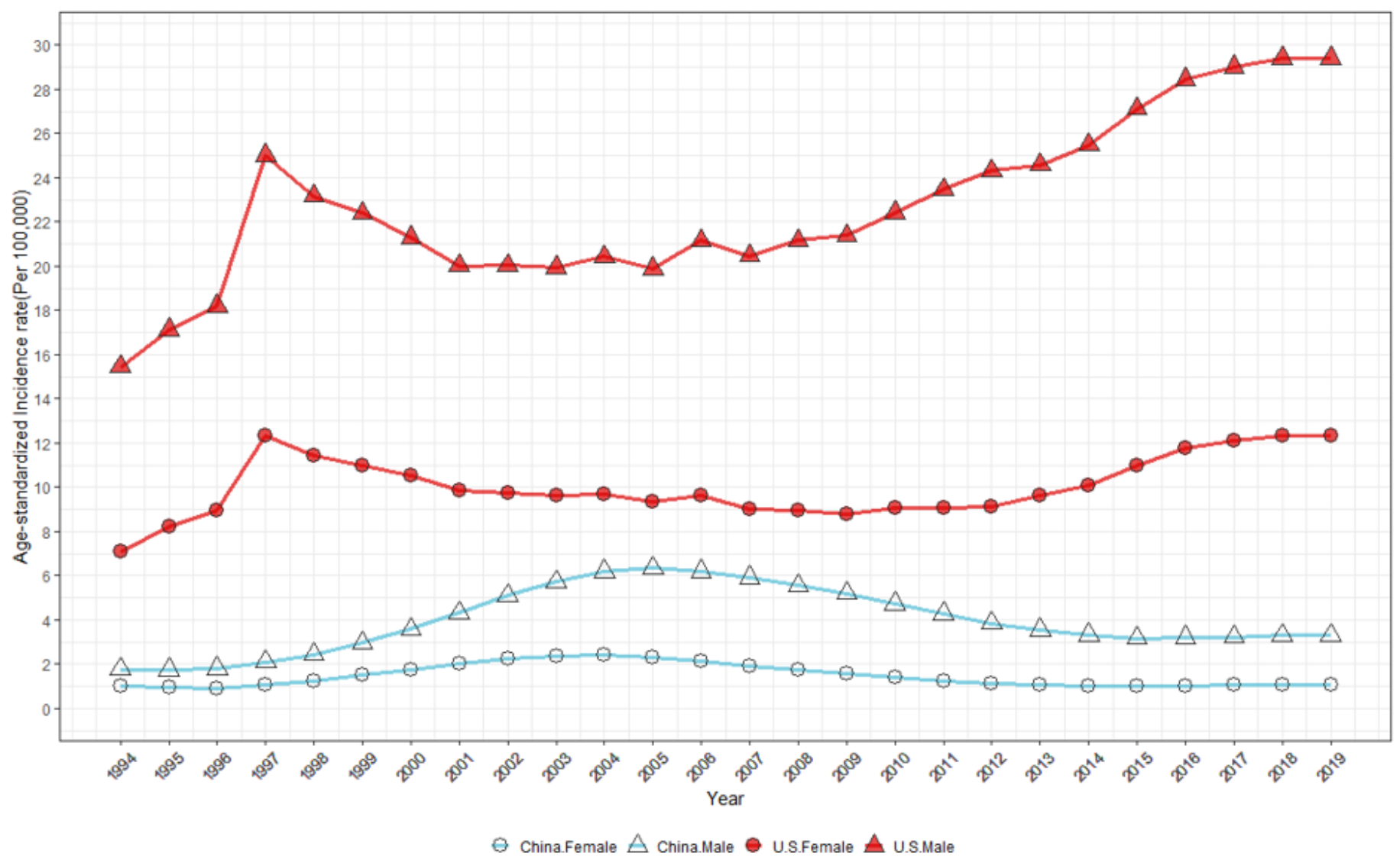

Figure 1

Age-standardized incidence rate for China and the U.S.,1994 to 2019 

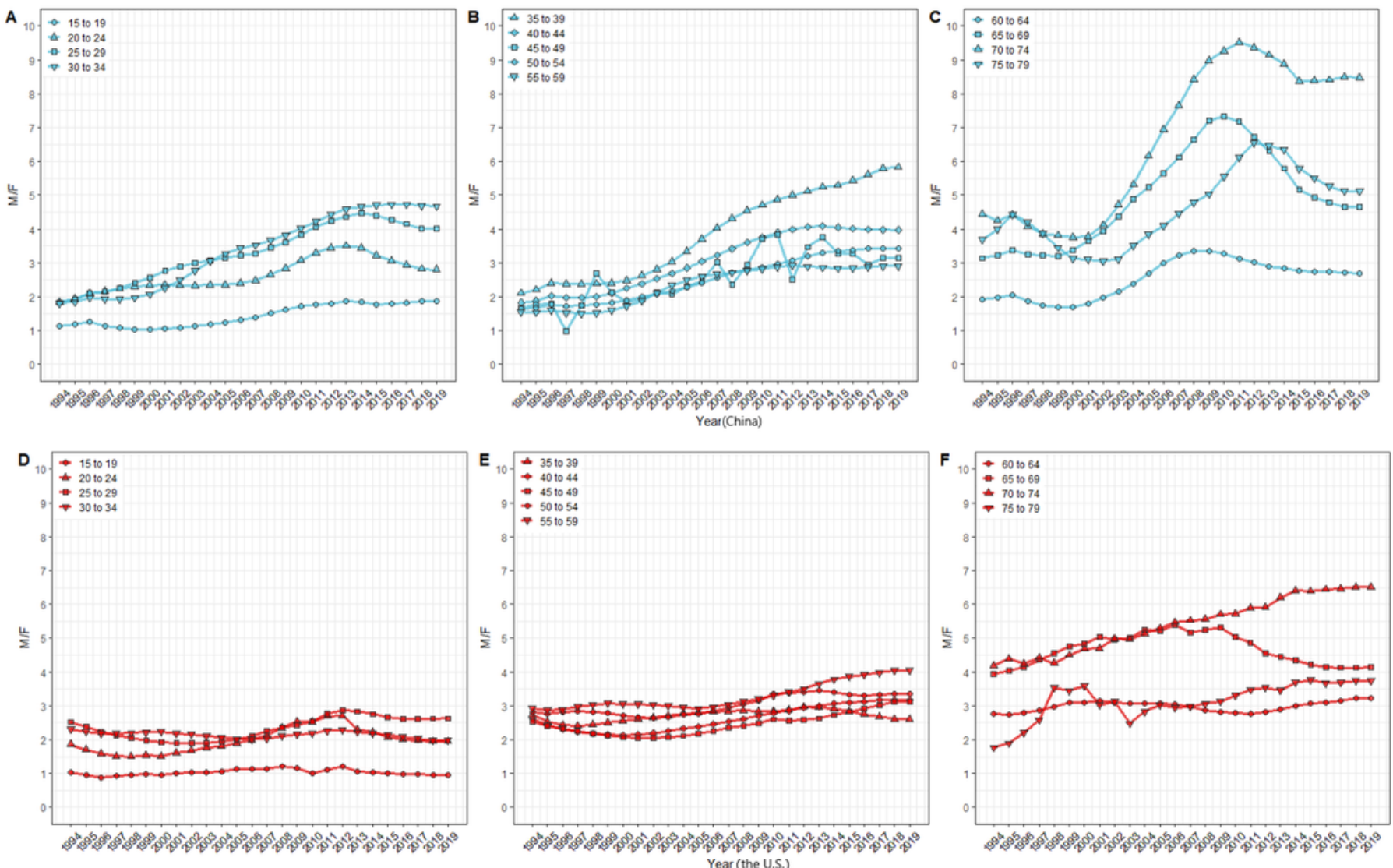

Figure 2

HIV/AIDS incidence rate ratios of males compared with females of young, middle and old age groups in China(A,B,C) and the U.S.(D,E,F), from 1994 to 2019. 

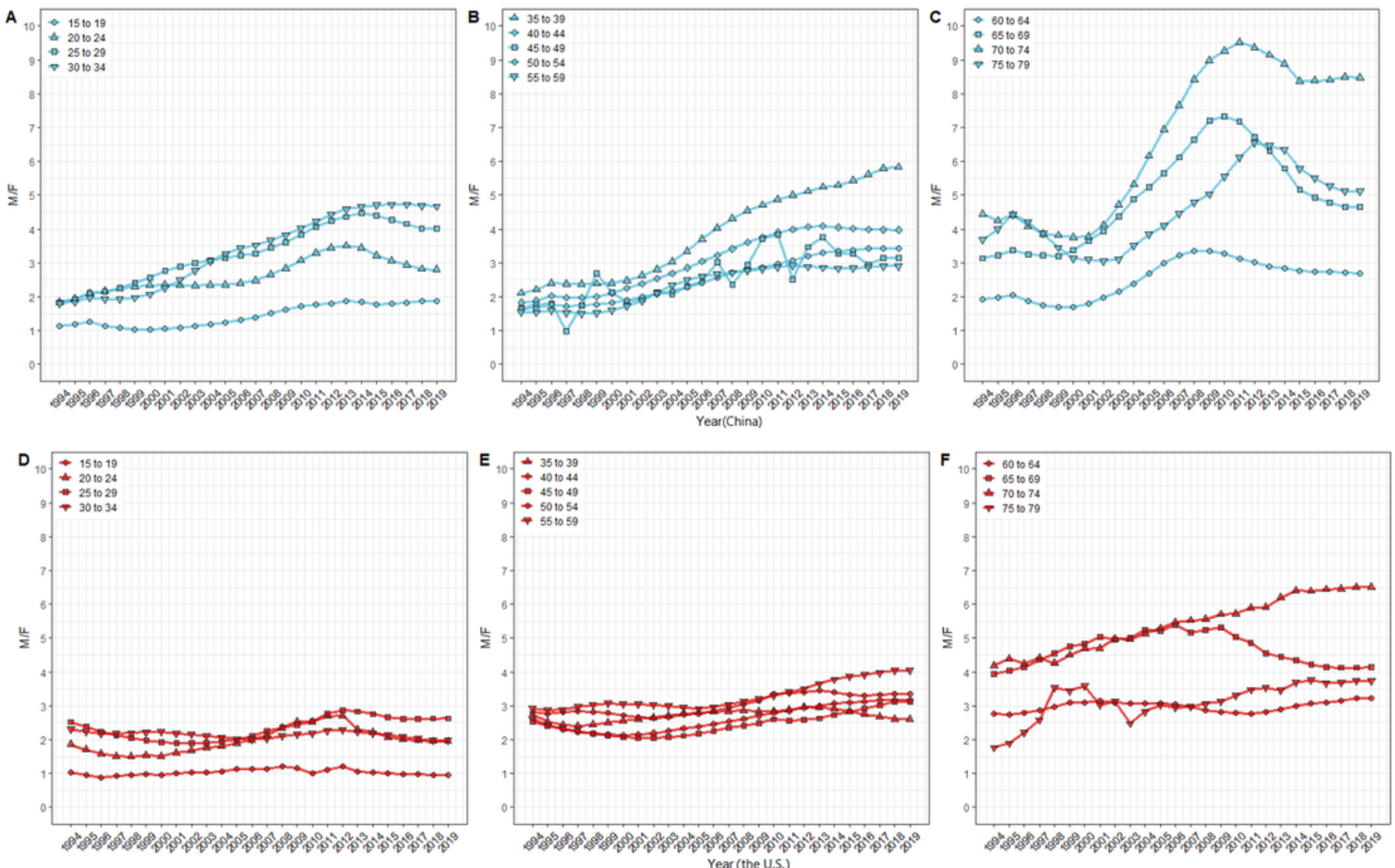

Figure 2

HIV/AIDS incidence rate ratios of males compared with females of young, middle and old age groups in China(A,B,C) and the U.S.(D,E,F), from 1994 to 2019. 


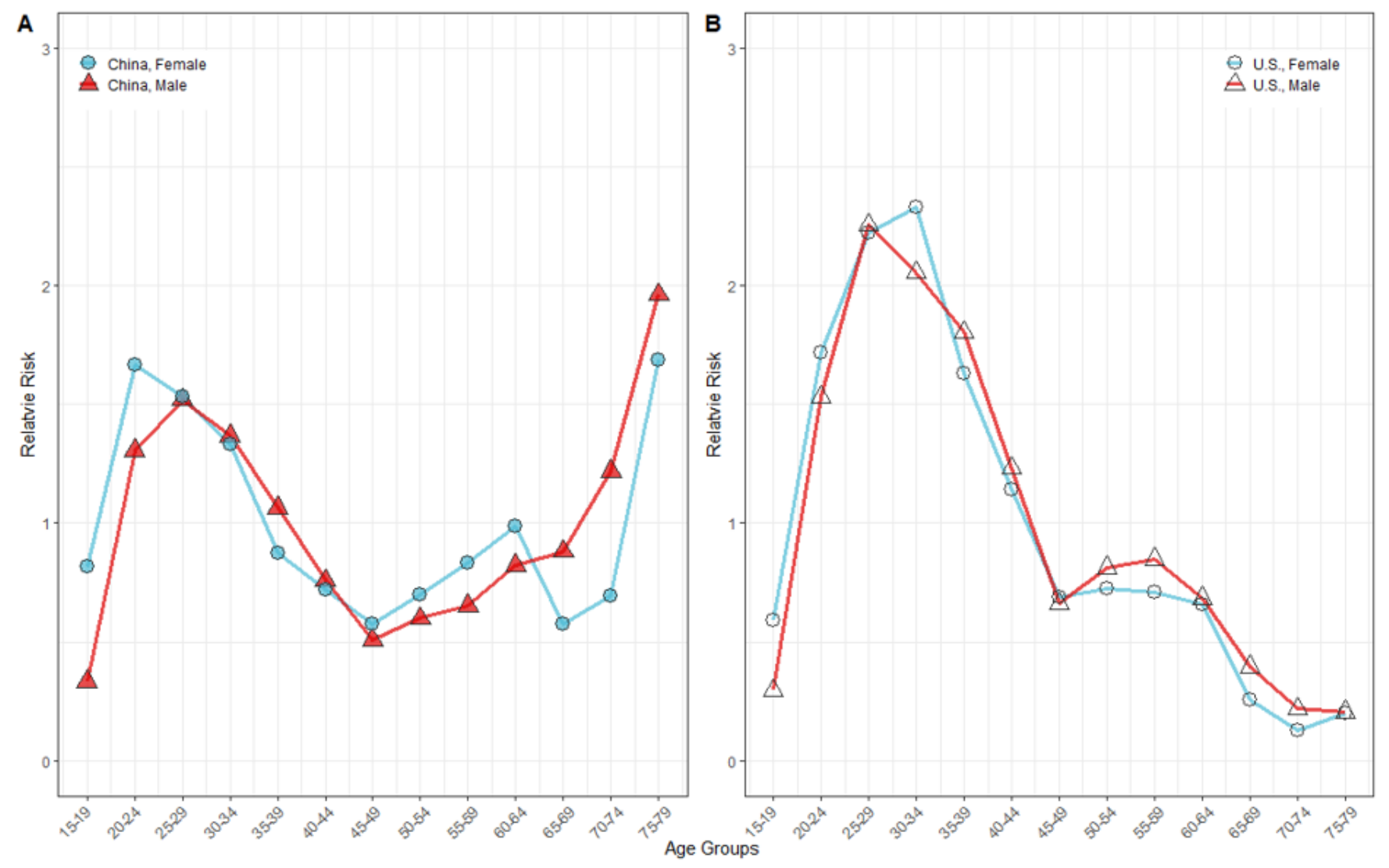

Figure 3

Age effect on HIV/AIDS incidence rate for male and female in China(A) and the U.S.(B), from 1994 to 2019 


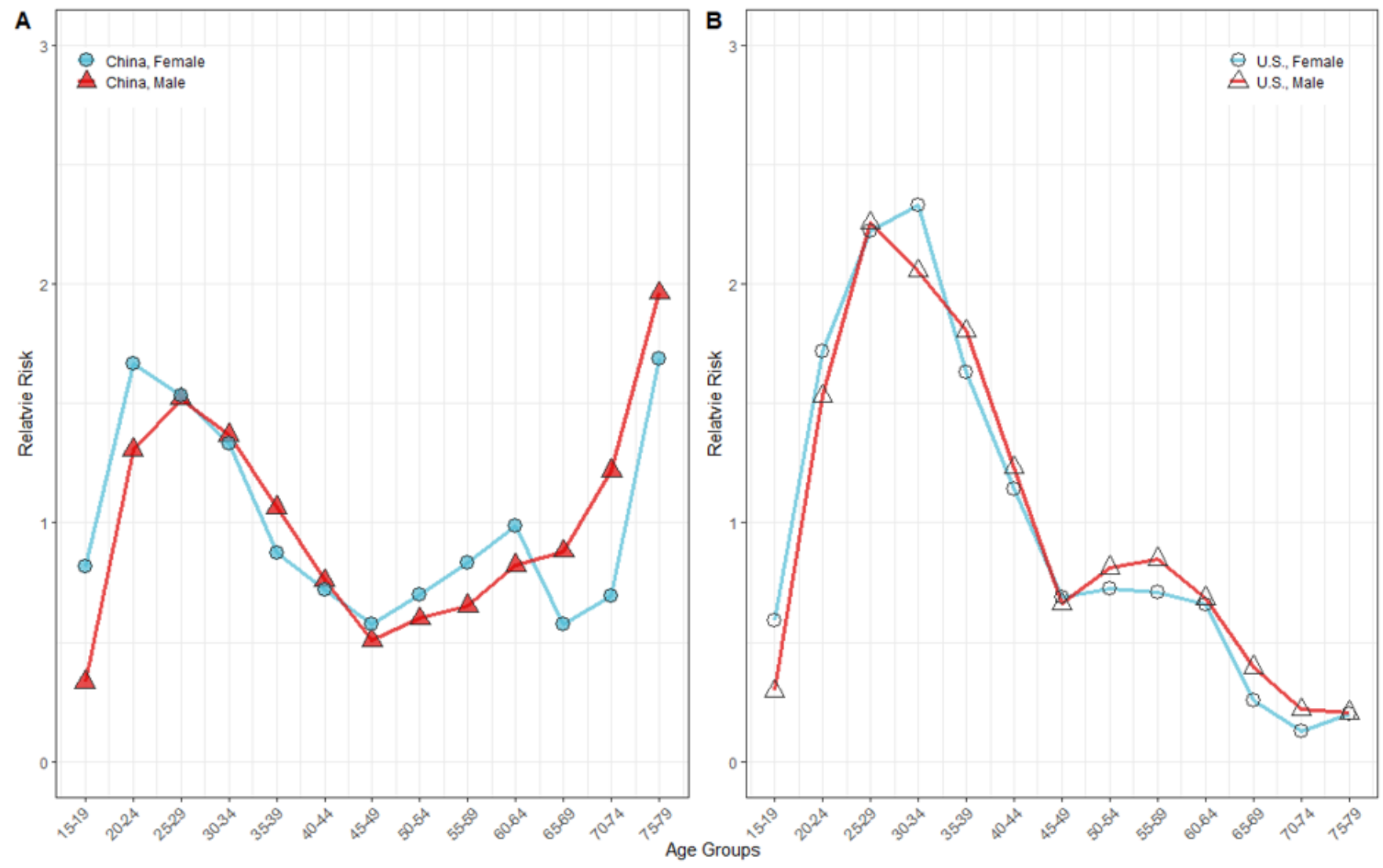

Figure 3

Age effect on HIV/AIDS incidence rate for male and female in China(A) and the U.S.(B), from 1994 to 2019 


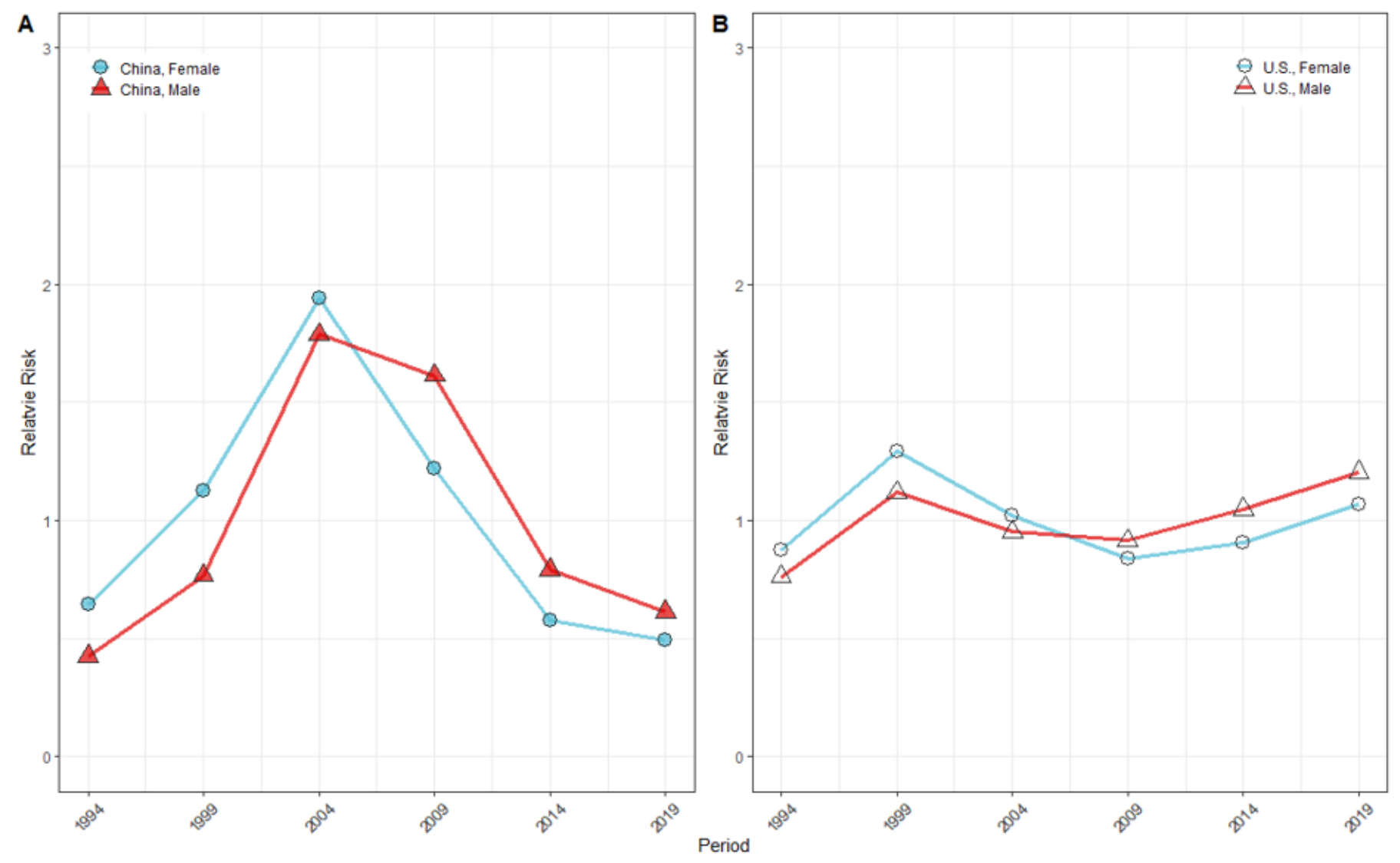

Figure 4

Period effect on HIV/AIDS incidence rate for male and female in China(A) and the U.S.(B), from 1994 to 2019 


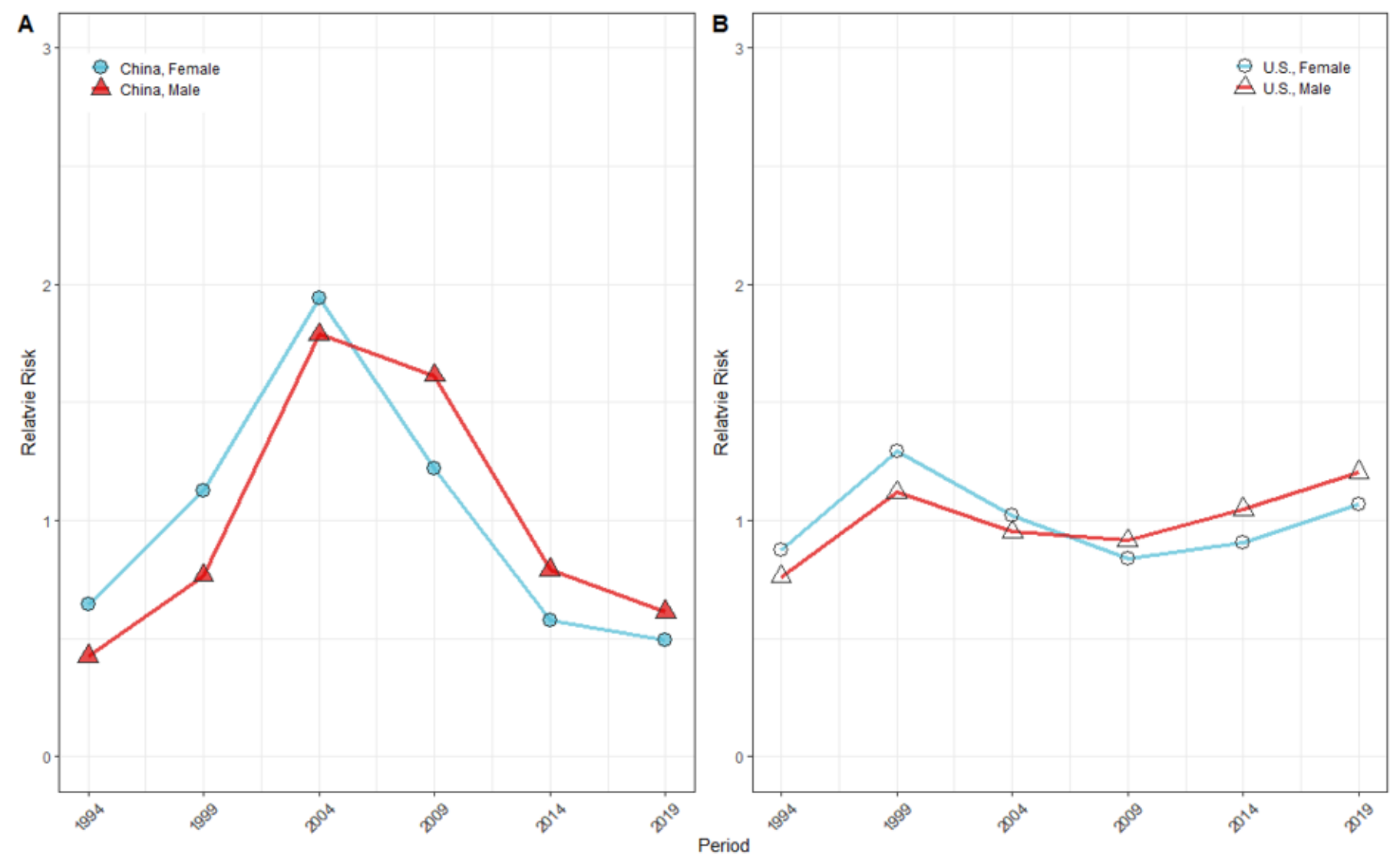

Figure 4

Period effect on HIV/AIDS incidence rate for male and female in China(A) and the U.S.(B), from 1994 to 2019 


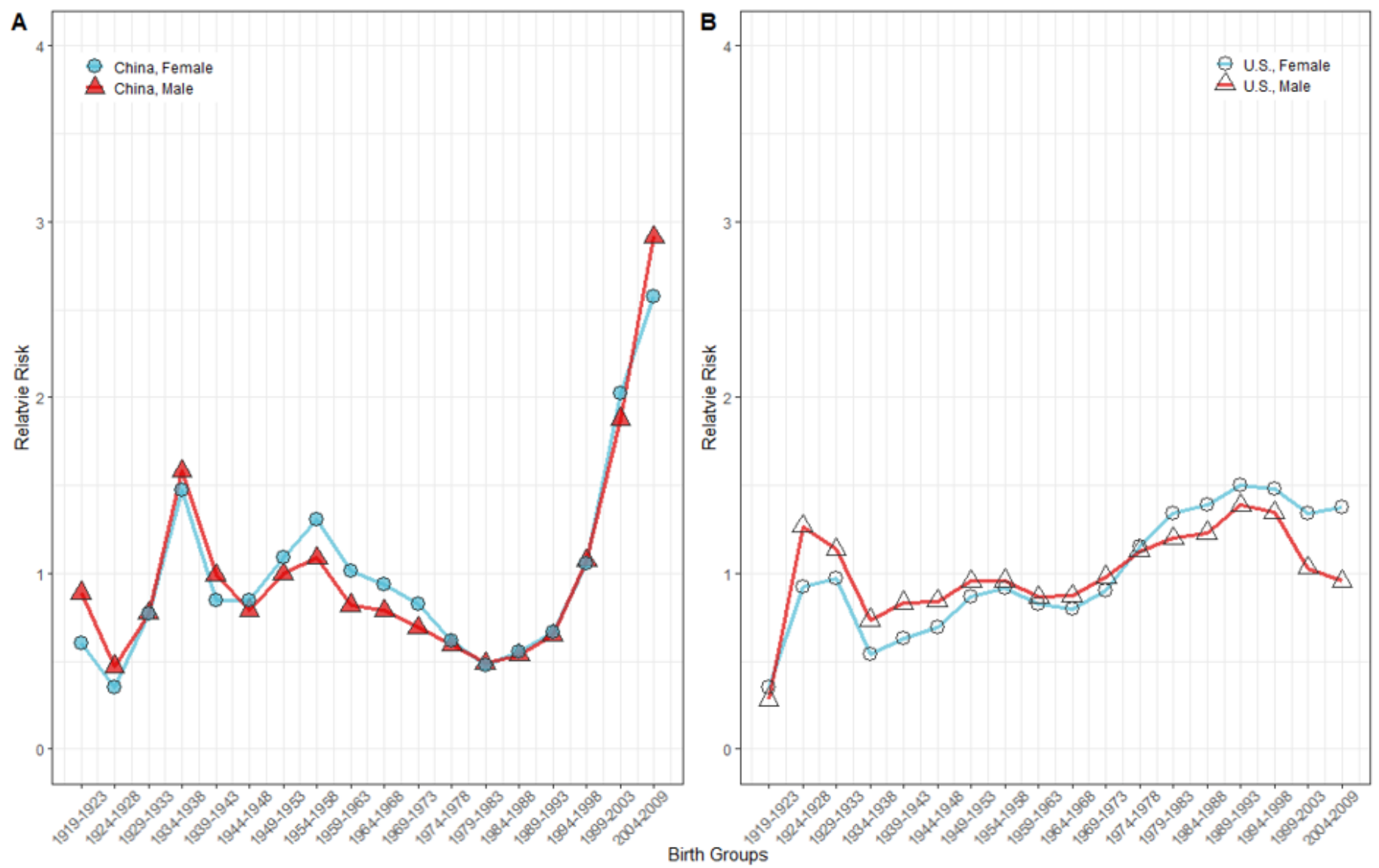

Figure 5

Cohort effect on HIV/AIDS incidence rate for male and female in China(A) and the U.S. (B), from 1994 to 2019 


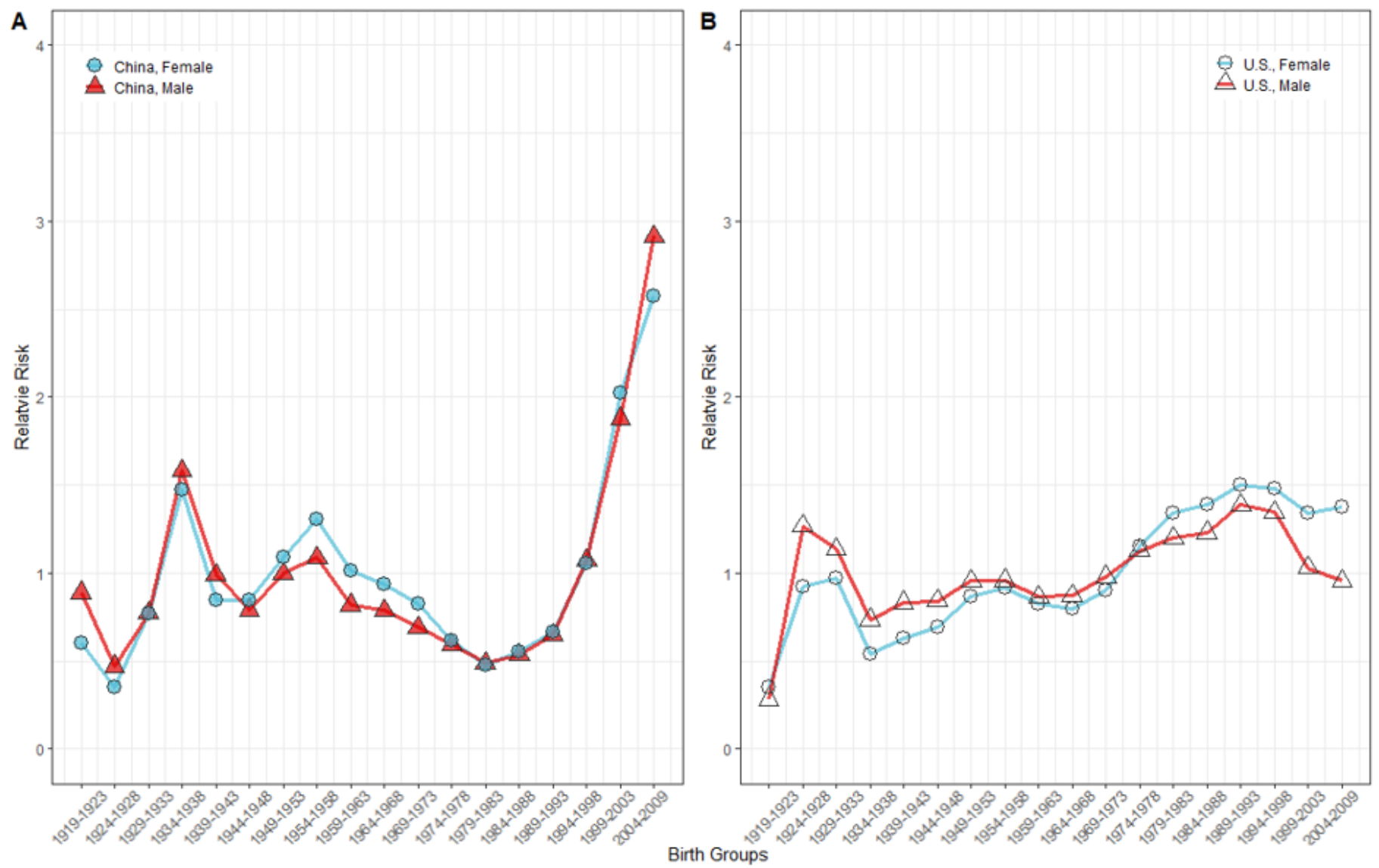

Figure 5

Cohort effect on HIV/AIDS incidence rate for male and female in China(A) and the U.S. (B), from 1994 to 2019

\section{Supplementary Files}

This is a list of supplementary files associated with this preprint. Click to download.

- Appendix.docx

- Appendix.docx 